\title{
The Effect of a Designed Teaching Module Regarding Prevention of Central-Line Associated Blood Stream Infection on ICU Nurses' Knowledge and Practice
}

\author{
Abeer El-Sol ${ }^{1,3}$, Amina I. Badawy ${ }^{2,3}$ \\ ${ }^{1}$ Medical Surgical Nursing, Faculty of Applied Medical Sciences, Al-Baha University, Al-Baha, Kingdom of Saudi Arabia \\ ${ }^{2}$ Medical Surgical Nursing, Faculty of Applied Medical Sciences, Al-Jouf University, Al-Jouf, Kingdom of Saudi Arabia \\ ${ }^{3}$ Adult Health Nursing, Faculty of Nursing, Menoufia University, Menoufia, Egypt
}

Email address:

amina73737373@yahoo.com (A. I. Badawy)

\section{To cite this article:}

Abeer El-Sol, Amina I. Badawy. The Effect of a Designed Teaching Module Regarding Prevention of Central-Line Associated Blood Stream Infection on ICU Nurses' Knowledge and Practice. American Journal of Nursing Science. Vol. 6, No. 1, 2017, pp. 11-18. doi: 10.11648/j.ajns.20170601.12

Received: December 8, 2016; Accepted: December 24, 2016; Published: January 19, 2017

\begin{abstract}
Background: The management for intensive care patients need to the insertion of central venous catheter, which has many dangerous complications, one of these complications is central-line associated blood stream infection which affects the patients' health status. Aim of the study: the study aimed to investigate the effect of a designed teaching module regarding prevention of central-line associated blood stream infection on ICU nurses' knowledge and practice through designed teaching module (theoretical \& practical for infection control measures). Methodology: A quasi-experimental research design used to achieve the study aim and pre/post-test was used. A convenience sample of 44 nurses working in Intensive Care Units. Two tools were used to collect data, I-Structured Interviewing Questionnaire: consists of two parts Part-A: Socio-demographic questionnaire \&Part-B: Structured questionnaire regarding knowledge of staff nurse to assess nurse's knowledge regarding prevention of central-line associated blood stream infection. II- An observational checklist. Results: the current study revealed that, most sample had nursing diploma. There were significant statistical differences were found between mean total knowledge score of studied sample pre-and post the educational module. Significant statistical differences were found in mean practice scores in post than pre-the educational module. There was a strong positive correlation was found among age, experience, knowledge and practice for studied nurses. Conclusion: Based on findings of the current study, it can be concluded that the improvement occurred in nurse's knowledge and practice after teaching of a designed module about infection control. Recommendations: Establishment educational programs centers in all hospitals which responsible updating and refreshing the nurses knowledge and practice; workshops which emphasizing on the evidence-based practices about infection control measures in critical settings within the hospitals, these services must be included the recently graduated nurses, the infection control department in hospital should follow up infection control process application in all hospital unities generally and critical unities especially.
\end{abstract}

Keywords: Central-Line Associated Blood Stream Infection, The National Patient Safety Goals, Prevention of Central-Line Associated Bloodstream Infection, Nurses Education and Training

\section{Introduction}

A central line is a catheter introduced into a large vein, it can be placed in veins in the neck (internal jugular vein), chest (subclavian vein, or axillary vein), groin (femoral vein), or through veins in the arms. It is also known as a central venous catheter $(\mathrm{CVC})$, central venous line, or central venous access catheter [1]. This catheter can be used to administer medication as long-term intravenous antibiotics, it usually remain in place for a longer period than other venous access devices, especially when the reason for their use is longstanding (such as total Parenteral nutrition in a chronically ill person), pain medications, drugs that are prone to cause phlebitis in peripheral veins such as calcium 
chloride, chemotherapy, dialysis and monitoring of the central venous pressure (CVP) in acutely ill people to quantify fluid balance, obtain blood tests (specifically the "central venous oxygen saturation") [1\&2].

When blood stream infection occurs with central line is serious, but preventable by evidence- based guidelines for central line insertion and maintenance are properly prioritized and implemented. The increasing inpatient length of hospital stay, cost and morbidity and mortality are the results of incidence of central line-associated bloodstream infections (CLABSIs) [3].

The source of central venous catheter infection depends on the type of used catheter and duration of use, there are two routes for catheter infection, the first route called extraluminally route, it common with short term nontunneled central venous catheter, in which the microorganisms enter the catheter lumen from the patient's skin causing colonization. The second route is intraluminally and the general main source of catheter infection, which occurred with long use of tunneled central venous catheters such as HICKMAN and BROVIAC-type catheters and peripherally inserted central catheter (PICCs) more than 10 days, the microorganisms enter the intravenous (IV) line through contaminated health care personnel hands during manipulation of intravenous system, or contamination with the patient's own body fluids or skin [4\&5].

Otherwise Insertion of central line may cause other numerous complications as pneumothrorax, which increase with insertion of subclavian vein catheterization [6]. The most common causative agents for blood stream infections are Staphylococcus aureus and Staphylococcus epidermidis sepsis [7].

The more serious healthcare-associated infection occurred in intensive care units are central line-associated bloodstream infections which lead to elevate in mortality rate and expenses $[7,8]$.

The incidence of central-line associated blood stream infection among adult ICUs patients ranged from 1.6 to 44.6 cases per 1,000 central line days, while neonatal ICUs patients ranged from 2.6 to 60.0 cases per 1,000 central line days, in addition the mortality rate ranging from 2.8 to 9.5 [9].

Central-line associated blood stream infection related to ICU detected after patient admission into intensive care unit by 2 days and discharge from it by less than 2 days. The infection occurs by three ways tip catheter colonization during insertion, or during care manipulation of catheter hub, or from blood stream and attaches lumen [10].

The prevention of Central-line associated blood stream infections (CLABSIs) need to use pre- insertion checklist for documentation of central venous catheter insertion and disinfection of intravenous (IV) access ports before use (scrub the hub),this checklist aimed to the goals for the national patient safety, and supported by many literatures, which suggested jugular lines is better site for insertion to reduce infection risks especially in obese people. When central-line associated blood stream infections occurred, the catheter should be removed and general antibiotics administered [11].

Prevention of catheter-related bloodstream infections among patients admitted into intensive care unit will improve patient's outcomes, and decrease admission duration in the hospital. There are different strategies to minimize catheterrelated bloodstream infections as central venous catheters manipulate into subclavian vein rather than other venous sites, change and rotate the antiseptic solution used for skin disinfection prior to catheter placing and make use of combination from different local application as polymyxin, neomycin and bacitracin ointment. Furthermore, organization of educational programs for health care provider's especially nursing staff about infection control measures and performance feedback [12].

Nurse's education and training are very necessary for them to gain the knowledge related to central venous catheters, assessment skills required to prevent complications of central venous access devices. For that reason, the current study aimed to investigate the effect of a designed teaching module regarding prevention of central-line associated blood stream infection on ICU nurses' knowledge and practice.

\subsection{Significance of the Study}

Extra than $48 \%$ of admitted intensive care unit patients during their admission need to central line insertion. So, these types of Patients in ICU have high risk factors for infection due to many reasons, central line is one of these factors by interrupt the skin continuity. The percentage of Patient death due to central-line associated blood stream infection range from $12 \%$ to $25 \%$ and the central-line associated blood stream infection treatment very costly, which ranged from $\$ 3,700$ to $\$ 36,000$ for every occurrence [13].

The interest with the problem of central line-associated bloodstream infections (CLABSI) has gained increasing in recent years.

Nurses in ICU have a vital role in reducing catheter-related bloodstream infection if they are well educated to use strategies to decrease central venous catheter infection rates which are based on the Centers for Disease Control and Prevention guidelines (CDC) to improve patient's outcomes.

The findings of the current study will provide a base of knowledge for ICU nurses on central venous catheter management, and ensure the highest standards of nursing management that is aiming at improving patients' outcomes. It is hoped that this effort might help nurses to improve their practice in assessment, planning, implementation and evaluation of such patients. This will reflect on shortening patient's length of stay, as well as decreasing hospital costs.

Moreover, it might generate an attention and motivation for further researches into this area.

\subsection{Aim of the Study}

The current study aimed to investigate the effect of a designed teaching module regarding prevention of centralline associated blood stream infection on ICU nurses' 
knowledge and practice.

\subsection{Research Hypotheses}

The following research hypotheses were formulated to achieve the aim of the study:

1. Implementation of a teaching module will increase nurses' knowledge regarding prevention of central-line associated blood stream infection.

2. The mean practice score of nurses regarding prevention of central-line associated blood stream infection post teaching will be higher than pre-teaching.

3. There will be an association among nurses' age, level of education and years of experience with their knowledge and practice scores regarding prevention of central-line associated blood stream infection.

\section{Subjects and Method}

\subsection{Design}

A quasi-experimental research design was utilized to achieve the aim of the study. A design of one group pre/posttest was used.

\subsection{Setting}

This study was conducted in female Intensive Care Units (ICU). In Prince Mutaip-Bin Abd el Aziz hospital.

\subsection{Subjects}

A convenience sample of 44 nurses working in Intensive Care Units were selected, total nurses in female ICU were 46, 2 nurses were in vacations and 44 nurses were on work. They provide care for patients admitted to the female ICU.

\subsection{Exclusion Criteria}

Nurses were excluded from the study if they: -

a Have already attended formal teaching module prevention of central-line associated blood stream infection.

b Not willing to participate in the study.

c Were in vacations.

\subsection{Tools for Data Collection}

Two tools were developed and used by the researchers to gather data relevant to the study. These tools are as follow:

\subsubsection{Structured Interviewing Questionnaire}

consists of two parts:

Part-A: Socio-demographic questionnaire prepared by investigator.

Part-B: Structured questionnaire regarding knowledge of staff nurse to assess nurse's knowledge regarding prevention of central-line associated blood stream infection. Entitled "Knowledge of Evidence-Based Guideline for Preventing Central Venous Catheter-Related Infection" developed by Labeau, et al., 2008 [14]. It is a reliable and valid questionnaire consists of 10 multiple choice questions; each question has 4 choices, only one is correct.

Each correct answer was given one score, for a total potential score range of 0 to 10 points per questionnaire.

\subsubsection{An Observational Checklist}

This checklist was developed by the researchers to assess nurses' practice for central-line management; it includes 10 statements to be checked by the researchers.

Each statement was given a score for each correct action, and zero for incorrect action, with total scores of 10 .

A pilot study was carried out before starting data collection on $10 \%$ of the sample, to evaluate the tentative developed tools for clarity and applicability, as well to estimate the time needed for data collection. Needed modifications were carried out. Validity of the Observational Checklist was determined by five experts to review these instruments and judge them to measure what was intended to be. reliability was tested by test retest for Observational Checklist.84.

\subsection{Method}

Official letters were issued to the director of the hospital and to the head of the intensive care unit, and then a written approval for carrying out the study was obtained after explaining the aim of the study.

Nurses were approached individually to explain the purpose and the nature of the study and to obtain their written consents for participation. Data collected throughout a period from January to June 2016.

\subsubsection{Procedures}

After preparation of the study tools and the educational materials include a simple illustrated Arabic booklet.

- Pre- test was done to determine baseline data for nurses' knowledge and practices.

- First, classification of nurses into (9) small groups; 15 nurses for each shift, nurses were divided into (8small groups, 5 nurses each, and (4 nurses in the last group), then nurses were oriented for objectives of the module.

- For teaching sessions: short interactive lectures and group discussions supported by audiovisual aids were conducted for each group. Each session lasted (20) minutes, they were six sessions were covered on two weeks. Continuous feedback and communication were assured to clear any misunderstanding, and, to reinforce learning these sessions followed by the performance part, which done through demonstration and redemonstrations utilized on top of using audiovisual aids, they were six for each group. Each session was lasted for 30 minutes, which were covered on 2 weeks.

- The researcher was available for 3 days/week at the intensive care unit at the three shifts for 90 minutes for each shift.

- Nurses were evaluated 3 times after the pretest. The first assessment was immediately after module implementation. 
The second test was on the $2^{\text {nd }}$ week and the last test was after 4 weeks from the immediate posttest.

\subsubsection{The Designed Teaching Module}

General Objectives:

Upon completion of this teaching module, the nurse will gain knowledge regarding CLABSI reduction practices based on the Healthcare Infection Control Practices Advisory Committee of the Centers for Disease Control and Prevention.

\section{Specific Objectives:}

Upon completion of this teaching module, the nurse will be able to:

1. Help health care personnel use best practices and improve their performance in handling CVCs.

2. Decrease in the incidence of Central-line associated blood stream infections among patients.

3. Provide ICU health care personnel with proposal included recommendations to improve surveillance systems, education and training in infection prevention and control

4. States were encouraged to develop plans to reduce the incidence of adverse events in all health care settings.

The teaching module consists of 3 phases

1. Phase (1) the researcher investigates the ICU nurses' knowledge about central lines and (CLABSI) (pretest)

2. Phase (2) Implement the researcher designed teaching module (theoretical \& practical for infection control measures)

3. Phase (3) Evaluate the effectiveness of designed teaching module (posttest)

Contents of designed teaching module

The designed teaching module based on categories and recommendations for CLABSI reduction practices from the Healthcare Infection Control Practices Advisory Committee of the Centers for Disease Control and Prevention.

Theoretical contents: Topics introduced: General information about central line, its uses and complications, nursing care, and patient teaching.

Timing: introduced through two weeks (2 sessions /week for each group) 20 minutes for each session so the contents given in 80 minutes through 4 sessions.

The practical contents: Hand hygiene, aseptic technique during catheter insertion; central venous site care and central line bundle dressings.

Timing: introduced through one-week (1 session /week for each group) half hour per the session, so the practical contents given in 30 minutes.

Date: the module begins at 15-1-2016 and ends at 15-52016.
Teaching methods: lecture, small group discussion, demonstration, and re-demonstration.

Audiovisual aids: PowerPoint slides, illustrated charts, illustrated Arabic booklet.

Evaluation: formative (quizzes and Asking questions) and summative (post-test).

\section{Statistical Analysis}

Data was presented using SPSS program in numbers, percentages, mean and standard deviation (SD), t-test, Pearson correlation analysis were used for assessment of the inter-relationships among quantitative variables, and one-way anova. Statistical significance was considered at p-value $<0.05$.

\section{Results}

Table (1) shows that the majority from the studied nurses $(59.09 \%)$ was aged in between twenty-nine to thirty-four years old with a mean age of $30.13 \pm 5$.7years.

Concerning to years of experience, more than half of studied nurses $(52.3 \%)$ had more than 10 years of experience. With respect to professional educational qualification, it was observed that $(43.2 \%)$ of them had bachelorette degree in nursing and $(56.8 \%)$ had nursing diploma.

Table (2)and Figure (1) show that mean total knowledge score of studied sample was 5.09 \pm .76Pre-teaching module. However, the mean score of total knowledge increased immediately after the teaching module and continued to be high at the next evaluation sessions $(9.86 \pm .69,9.16 \pm .49$ and $9.66 \pm .56$ respectively) (statistically significant, $\mathrm{p}<0.001$ ). Hypothesis 1 was supported by the data.

Table (3) and Figure (2) show that mean total score of practice of studied sample was 5.91土.93Pre-teaching module. However, the mean score of total practice increased immediately after the teaching module and continued to be high at the following evaluation sessions $(9.98 \pm .99,9.86 \pm .69$ and $9.96 \pm .66$ respectively) (statistically significant, $\mathrm{p}<0.001$ ). Hypothesis 2 was supported by the data.

Table (4) illustrates that nurses who were more than 34 years had significantly the greatest mean total knowledge score, the more experienced nurses, and nurses who had bachelorette degree in nursing, had more mean total knowledge score than who had nursing diploma.

Table (5) it is obvious that from this table, there is a strong positive correlation was found among age, experience, knowledge and practice for studied nurses. Hypothesis 3 was supported by the data.

Table 1. Distribution of demographic characteristics of the studied nurses.

\begin{tabular}{|c|c|c|}
\hline \multirow{2}{*}{ Demographic characteristics } & \multicolumn{2}{|c|}{ Studied Nurses $N=44$} \\
\hline & No & $\%$ \\
\hline \multicolumn{3}{|l|}{ Age (years) } \\
\hline 23- & 11 & 25 \\
\hline
\end{tabular}




\begin{tabular}{lll}
\hline \multirow{2}{*}{ Demographic characteristics } & Studied Nurses $\mathbf{N}=\mathbf{4 4}$ & \% \\
\cline { 2 - 3 } 29- & No & 59.09 \\
More than 34 & 26 & 15.90 \\
X \pm SD & 7 & \\
Years of experience & $30.13 \pm 5.7$ & 25 \\
$\mathbf{1 -}$ & & 22.7 \\
6- & 11 & 52.3 \\
More than 10 years & 10 & \\
X \pm SD & 23 & 56.8 \\
Levels of education & $11.66 \pm 5.08$ & 43.2 \\
Nursing diploma & & 25 \\
Bachelorette degree & 19 & \\
\hline
\end{tabular}

Table 2. Total knowledge scores among studied Nurses pre-and post-teaching.

\begin{tabular}{|c|c|c|c|c|c|c|c|c|c|}
\hline \multirow{2}{*}{ Knowledge score } & \multicolumn{2}{|c|}{ Pre teaching $N=44$} & \multicolumn{2}{|c|}{$\begin{array}{l}\text { Immediate post teaching } \\
\mathrm{N}=44\end{array}$} & \multicolumn{2}{|c|}{$\begin{array}{l}\text { Two weeks post teaching } \\
\mathrm{N}=44\end{array}$} & \multicolumn{2}{|c|}{$\begin{array}{l}\text { Four weeks post teaching } \\
\mathrm{N}=44\end{array}$} & \multirow[t]{2}{*}{$\operatorname{ANOVA}(F) / p$ values } \\
\hline & Mean & $\pm \mathbf{S D}$ & Mean & \pm SD & Mean & \pm SD & Mean & \pm SD & \\
\hline Mean \pm SD & $5.09 \pm .76$ & & $9.86 \pm .69$ & & $9.16 \pm .49$ & & $9.66 \pm .56$ & & $851 * * *$ \\
\hline
\end{tabular}

$* * *$ Significant at 0.001

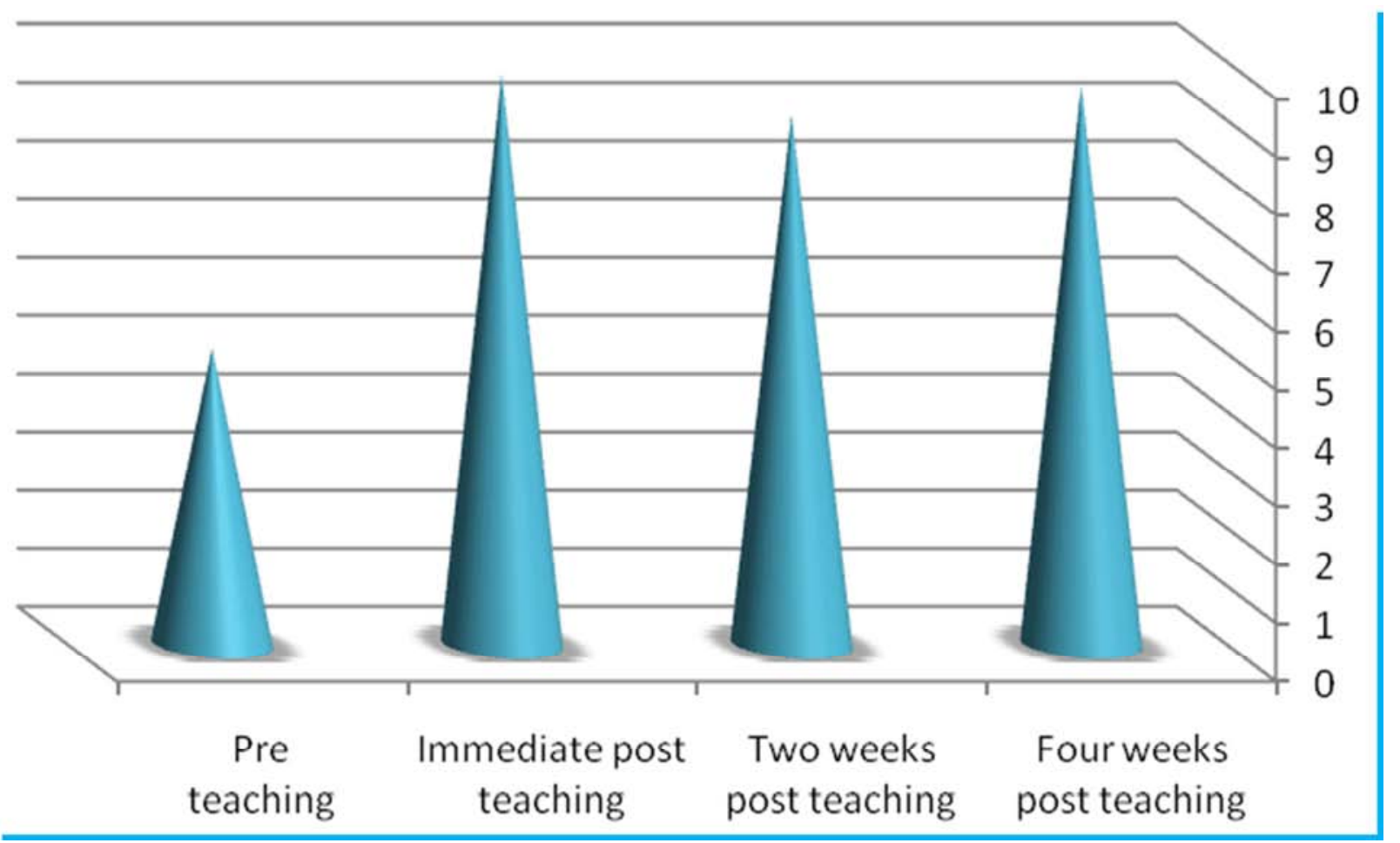

Figure 1. Total mean knowledge scores among studied Nurses throughout study phases.

Table 3. Total practice scores among studied nurse's pre-and post-teaching.

\begin{tabular}{|c|c|c|c|c|c|c|c|c|c|}
\hline \multirow{2}{*}{ practice score } & \multicolumn{2}{|c|}{$\begin{array}{l}\text { Pre teaching } \\
\mathrm{N}=44\end{array}$} & \multicolumn{2}{|c|}{$\begin{array}{l}\text { Immediate post teaching } \\
\mathrm{N}=44\end{array}$} & \multicolumn{2}{|c|}{$\begin{array}{l}\text { Two weeks post teaching } \\
\mathrm{N}=44\end{array}$} & \multicolumn{2}{|c|}{$\begin{array}{l}\text { Four weeks post teaching } \\
N=44\end{array}$} & \multirow[t]{2}{*}{$\begin{array}{l}\operatorname{ANOVA}(\mathrm{F}) / \mathrm{p} \\
\text { values }\end{array}$} \\
\hline & Mean & \pm SD & Mean & \pm SD & Mean & \pm SD & Mean & \pm SD & \\
\hline
\end{tabular}

$* * *$ Significant at 0.001 


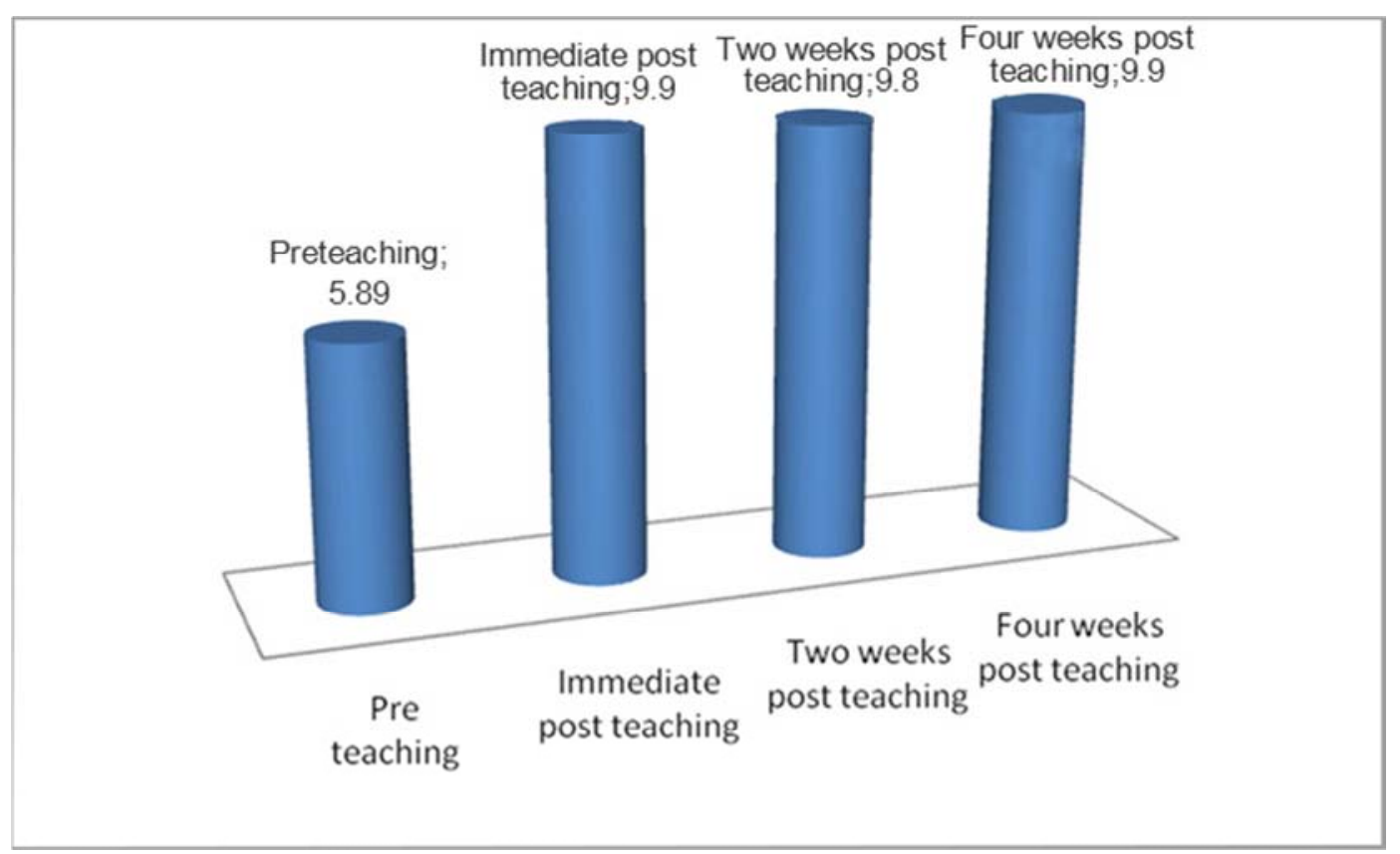

Figure 2. Total mean practice scores among studied Nurses throughout study phases.

Table 4. Mean knowledge score by studied nurses and selected demographic variables. (N=44).

\begin{tabular}{|c|c|c|c|c|c|c|c|c|}
\hline \multirow[t]{2}{*}{ Knowledge score } & \multicolumn{2}{|c|}{ Pre teaching $N=44$} & \multicolumn{2}{|c|}{ Immediate post teaching $N=44$} & \multicolumn{2}{|c|}{ Two weeks post teaching $N=44$} & \multicolumn{2}{|c|}{ Four weeks post teaching $N=44$} \\
\hline & Mean & \pm SD & Mean & $\pm \mathrm{SD}$ & Mean & $\pm \mathrm{SD}$ & $\pm \mathrm{SD}$ & Mean \\
\hline \multicolumn{9}{|l|}{ Age (years) } \\
\hline 23- & $4.93 \pm .56$ & & $9.89 \pm .79$ & & $9.77 \pm .46$ & & $9.66 \pm .56$ & \\
\hline 29- & $5.09 \pm .77$ & & $9.86 \pm .69$ & & $9.66 \pm .39$ & & $9.66 \pm .56$ & \\
\hline More than 34 & $5.19 \pm .96$ & & $9.99 \pm .79$ & & $9.96 \pm .69$ & & $9.96 \pm .69$ & \\
\hline \multicolumn{9}{|l|}{ Years of experience } \\
\hline $1-$ & $5.33 \pm .66$ & & $8.87 \pm .59$ & & $9.77 \pm .46$ & & $9.66 \pm .56$ & \\
\hline $6-$ & $5.22 \pm .67$ & & $9.83 \pm .69$ & & $9.66 \pm .39$ & & $9.66 \pm .56$ & \\
\hline More than 10 years & $5.99 \pm .99$ & & $9.89 \pm .78$ & & $9.94 \pm .68$ & & $9.93 \pm .67$ & \\
\hline Levels of education & & & & & & & & \\
\hline Nursing diploma & $4.90 \pm .55$ & & $9.89 \pm .79$ & & $9.77 \pm .46$ & & $9.66 \pm .56$ & \\
\hline Bachelorette degree & $6.09 \pm .87$ & & $10 \pm .83$ & & $9.96 \pm .79$ & & $9.99 \pm .80$ & \\
\hline
\end{tabular}

Table 5. Correlation matrix of age, experience, knowledge and Practice of studied Nurses $(n=44)$.

\begin{tabular}{lllll}
\hline Item & Age & Experience & Knowledge & Practice \\
\hline Age & 1.00 & & & \\
Experience & $.91 * *$ & 1.00 & & \\
Knowledge & $.80^{* *}$ & $.82 * *$ & 1.00 & \\
Practice & $.81 * *$ & $.87 * *$ & $.81 * *$ & 1.00 \\
\hline
\end{tabular}

\section{Discussion}

The current study aimed to investigate the effect of a designed teaching module regarding prevention of centralline associated blood stream infection on ICU nurses' knowledge and practice. Findings of the current study revealed that mean total knowledge score of studied sample was $5.09 \pm .76$ in Pre-teaching module. However, the mean score of total knowledge increased immediately after the teaching module and continued to be high in the next evaluation sessions, with considerable difference in the nurses' knowledge before and after the designed teaching module, and the positive change in the nurses' knowledge reflected that education could make change in knowledge level regarding prevention of central-line associated blood stream infection and showed a considerable difference in the nurses' knowledge before and after the designed teaching module. These results were supported by hypothesis 1 .

Moreover, the present study results were agreed with many previous studies as Uba et al., 2015; [15] Deshmukh and Shinde, 2014; [16] Pushpakala and Ravinath, 2014; [17] Bianco et al., 2013; [18] Shrestha, 2013; [19] and Meherali et al., 2011[20] they showed nurses' knowledge influenced by professional education and training. In the same line, Cooper, et al., 2014; [21] and Kim et al., 2011 [22] they said that the implementation of educational program, lead to decrease the incidence rate of catheter-related bloodstream infection, and its cost. The current results supported by Kadium 2015 [23] who stated that formal training contributed to an increase in knowledge, practice, and positive attitudes toward catheter- 
related bloodstream infection prevention.

As well, the current study findings revealed that, mean total score of practice of studied sample was 5.91土.93Preteaching module. However the mean score of total practice increased immediately after the teaching module and continued to be high at the following evaluation sessions, and Hypothesis 2 was supported by the data, in the light of the current study, Chu, et al., 2013 [24] they established that dialysis nurses have a significant role in preventing of catheter-related bloodstream infection which was an extensive spread, and can be avoidable complication by application of fundamental infection control measures and must follow an effective central venous catheter care. In addition, Kable, et al., 2011 [25] \& Ebied, (2011) [26] they found that most of studied nurses attended in-service training courses about infection control their knowledge and practice increased. Nurse attendance of tutoring courses and training programs keeping them up-to-date and enhancing their practices particularly in applying the procedures that need to strict aseptic techniques.

It is apparent from study findings that, nurses who were more than 34 years had significantly the greatest mean total knowledge score, the more experienced nurses, the significance greater mean total knowledge score, and nurses who had bachelorette degree in nursing had more mean total knowledge score than who had nursing diploma. Furthermore, the findings of the existing study reported that, there is a strong positive correlation was found among age, experience, knowledge and practice for studied nurses. Hypothesis 3 was supported by the data.

Bianco et al., 2013; [27] Parra et al., 2010; [28] Evans \&Donnelly, 2006; [29] they documented that many sources could increase knowledge as basic and continuing education, training, personal experience, or in-service training.

The results were consistent with Royal College of Nursing $(\mathrm{RCN}) ; 2012$ [30] which clarified that health facilities as work place must contain written policies regarding types of standard precautions used for infection control, which make available direction on all aspects of critically ill patients' care. As well, ongoing tutoring despite the age can significantly improve infection control practices and low the incidence rate of infection.

The present result was agreement with Labrague, et al., 2012 [31] they found in their study about knowledge and compliance with standards precautions that the young age of the studied sample had capability to gain knowledge and alter their behaviors. While Alwutaib et al., 2012 [32] they stated that older age is an important indicator to lesser knowledge levels.

\section{Conclusion}

The current study concluded that knowledge and practice of ICU nurses were insufficient at the pre-program implementation, while the improvement of their knowledge and practice occurred after program implementation. On the other hand, it was observed that there was an association between age, years of experience, and knowledge of nurses.

\section{Recommendations}

The study recommended establishment educational programs centers in all hospitals which responsible updating and refreshing the nurses' knowledge and practice; workshops which emphasize on the evidence-based practices about infection control measures in critical settings within the hospitals, these services must be included the recently graduated nurses, the infection control conduct similar studies by including additional demographic variables.

\section{References}

[1] McKean, Sylvia; Ross, John; Dressler, Daniel; Brotman, Daniel; Ginsburg, Jeffrey (2012). Principles and practice of hospital medicine. New York: McGraw-Hill. ISBN 9780071603898 .

[2] Weinstein, R. A. (2015). Infections Acquired in Health Care Facilities. New York, NY: McGraw-Hill. ISBN 0071802150.

[3] Centers for Disease Control and Prevention (2015). Bloodstream Infection Event (Central Line-Associated Bloodstream Infection and Non-central line-associated Bloodstream Infection).

[4] O'Grady NP, Alexander M, Burns LA, Dellinger EP, Garland J, Heard SO, Lipsett PA, Masur H, Mermel LA, Pearson ML, Raad II, Randolph AG, Rupp ME, Saint S; Healthcare Infection Control Practices Advisory Committee (HICPAC). Guidelines for the prevention of intravascular catheter-related infections. Clin Infect Dis. 2011; 52 (9): e162-193. Epub 2011.

[5] Mermel LA. What is the predominant source of intravascular catheter infections? Clin Infect Dis. 2011 Jan 15; 52 (2): 211212.

[6] National Institute for Health and Clinical Excellence (2002) "Technology appraisal: the clinical effectiveness and cost effectiveness of ultrasonic locating devices for the placement of central venous lines". Retrieved 2008-06-01.

[7] Murray E. C., Deighan C., Geddes C., Thomson P. C. (2014). Taurolidine-citrate-heparin catheter lock solution reduces staphylococcal bacteremia rates in Hemodialysis patients. QJMed2014.

[8] Weber DJ, Rutala WA. Central line-associated bloodstream infections: prevention and management. Infect Dis Clin North Am. 2011; 25 (1): 77-102. [Pub Med].

[9] Rosenthal VD. Central line-associated bloodstream infections in limited-resource countries: a review of the literature. Clin Infect Dis. 2009; 49 (12): 1899-907. [Pub Med].

[10] Band, J. (2010). Pathogenesis of and risk factors for central venous catheter-related infections. Retrieved from http://www.uptodate.com/online/content/topic.do?topicKey=h osp_inf $/ 6194 \&$ view $=$ print.

[11] Parienti JJ; Thirion M; Mégarbane B; et al. (May 2008). "Femoral vs. jugular venous catheterization and risk of nosocomial events in adults requiring acute renal replacement therapy: a randomized controlled trial". JAMA 299 (20): 2413-22.doi:10.1001/jama.299.20.2413. PMID 18505951. 
[12] RamrituP, HaltonK, CookD, WhitbyM, GravesN. Catheterrelated bloodstream infections in intensive care units: a systematic review with meta-analysis. J Adv Nurs. 2008 Apr; 62 (1): 3-21. Retrieved from http://www.cdc.gov/nhsn/PDFs/pscManual/4PSC CLABScurr ent.Pdf.

[13] Scott, R. D. (2009). The Direct Medical Costs of HealthcareAssociated Infections in U. S. Hospitals and the Benefits of Prevention. Atlanta, GA: Division of Healthcare Quality Promotion, Centers for Disease Control and Prevention. Retrieved from http://www.cdc.gov/hai/pdfs/hai/scott_costpaper.pdf.

[14] Labeau, S., Vereecke, A., Vandijck, A, Claes, B., \& Blot, S. I. (2008). Critical care nurses' knowledge of evidence-based guidelines for preventing infections associated with central venous catheters: An evaluation questionnaire. American journal of critical care 17 (1), 65-71.

[15] Uba, M. N., Alih, F. I., Kever, R. T., \& Lola, N. (2015). Knowledge, attitude and practice of nurses toward pressure ulcer prevention in University of Maidugubi teaching hospital, Borno tate, north-eastern, Nigeria. Hnternational Journal of Nursing and Midwiferq, 7 (4), 54-60. doi: 10.5897/IJNM2014. 0155.

[16] Deshmukh, M., \& Shinde, M. (2014). Impact of structured education on knowledge and practice regarding venous access device care among nurses. Interfational Journal of Science and Research, 3 (1), 895-901. Retrieved from http://www.ijsr.net/archive/v3i5/MDIwMTMxOTYw.pdf

[17] Pushpakala, K. J., \& Ravinath, A. (2014). Effectiveness of self-instructional module on central venous catheter care among ICU nurses. Journal of Nursang and Health Science, 3 (5), 3234. Retrieved fromwww.iosrjournals.org.

[18] Bianco, A., Coscarelli, P., Nobile, C. G., Pileggi, C., \& Pavia, M. (2013). The reduction of risk in central line-associated bloodstream infections: Kngwledge, attitudes, and evidencebased practices in 'ealth care workers. American Journal of Infection Control, 41 (2) (107-112. doi: 10.1016/j.ajic.2012.02.038.

[19] Qhrestha, R. (2013). Impact of educational interventions on nurses' knowledge regarding care $\mathrm{kf}$ the patient vith central venous line. Journal of Kathmandu Medical College, Vol. 2. No. 1. Issue 3. DOI: http://dh.doi.org/10.3126/jkmc.v2i1.10553.

[20] Meherali, S. ., Parpio, I., Ali, T. S., \& Javed, F. (2011). Nurses' knowledge of evidence-based guidelines fgr prevention of ventilator associatad pneumonia in critical cabe areas: a pre-and post\%test design. $J$ Ayub Med Coll Abbottabad, 23 (1), 146-). Retrieved from http://ayubmed.edu.pk/JAMC/23-1/Salima.pdb.

[21] Cooper, K., Frampton, G., Harris, P., Jones, J., Cooper, T., Graves, N., \& Cuthbertsof, B. H. (2014). Are educational interventions tk prevent catheter-related bloodstream infections in intensive care unit cost-effective? Journal of Hospital Infection, 86 (1), 47-52. doi:

10.1016/j.jhin.2013.09.004.

[22] Kim, J. S., Holtom, P., \& Vigen, C. (2011). Reduction of catheter-related bloodstream infections using a central venous line bundle: Epidemiologic and economic consequences.
American Journal of Infection Control, 39 (8), 640- 646.doi: 10.1016/j.ajic.2010.11.005.

[23] Kadium, J. M. (2015). Improving Nurses' Knowledge to Reduce Catheter- Related Bloodstream Infection in Hemodialysis Unit. Project Submitted in Partial Fulfillment of the Requirements for the Degree of Doctor of Nursing Practice. Walden University Follow this and additional works at: http://scholarworks.waldenu.edu/dissertations.

[24] Chu, G., Adams, K., \& Crawford, S. (2013). Improving catheter-related bloodstream infection in Hemodialysis patients using a practice development framework. Renal Society of Australasia Journal, 9 (1), 16-21. Retrieved from http://www.renalsociety.org/Resources/Documents/RSAJ/201 3.03/Chu.pdf.

[25] Kable, Guset, Mcleod, (2011). Organizational risk management and nurses' perceptions of workplace risk associated with sharps including needle stick injuries in nurses in new south Wales, Australia. Nurse Health Sci Faculty of Health, University of Newcastle, New South Wales nurses' association Sydney, New South Wales, Australia.

[26] Ebied, E. (2011). Impact of blood-borne diseases prevention program on compliance with infection control standard precautions among nurses in family health centers, El Fayoum Governorate, Egypt.

[27] Bianco, A., Coscarelli, P., Nobile, C. G., Pileggi, C., \& Pavia, M. (2013). The reduction of risk in central line-associated bloodstream infections: Knowledge, attitudes, and evidencebased practices in health care workers. American Journal of Infection Control, 41 (2), 107-112. doi: 10.1016/j.ajic.2012.02.038.

[28] Parra, A., P., Granda, M., P., Padilla, M., P., B., \& Bouza, E. (2010). A simple educational intervention to decrease the incidence of central line-associated bloodstream infection (CLABSI) in intensive care units with low baseline incidence of CLABSI. Infection Control and Hospital Epidemiology, 31 (9), 964-967. doi:10.1017/S019594170003887X.

[29] Evans, R. J., \& Donnelly, G. W. (2006). A model to describe the relationship between knowledge, skill, and judgment in nursing practice. In Nursing Forum (vol. 41, no. 4, pp. 150157). Blackwell Publishing Inc. doi: 10.1111/j.17446198.2006.00053.x.

[30] Royal College of Nursing (2012). Essential practice for infection prevention and control Guidance for nursing staff, London: RCN. Publication code: 004166.

[31] Labrague L. J., Rosales R. A., \& Tizon M. M. (2012). Knowledge of and compliance with standards precautions among student nurses. International journal of advanced nursing studies. 1 (2): 84-97. www.sciencepubco.com/index.php/IJANS.

[32] Alwutaib A. H., Abdulghafour Y. A., Alfadhli A. K., Makboul G., El-Shazly M. K. (2012). Knowledge and attitude of the physicians and nurses regarding blood borne infections in primary health care, Kuwait. Greener Journal of Medical Sciences., 2 (4): 107-114. 